\title{
Quantifying the impact of mathematics support on the performance of undergraduate engineering and computing students
}

Calum Macdonald, School of Computing, Engineering and Built Environment, Glasgow Caledonian University, Glasgow, UK. Email: calum.macdonald@gcu.ac.uk

\begin{abstract}
The School of Computing, Engineering and Built Environment at Glasgow Caledonian University has provided mathematics support for all students in the school since 2012/13. This paper compares the performance of two groups of undergraduate students; those who engaged with mathematics support, through attending targeted lectures, and those who chose not to engage. Data collected over the five years from $2013 / 14$ to $2017 / 18$ for 4,690 engaging and non-engaging students, enrolled on modules with a substantial mathematical content, were analysed. Module marks achieved at first diet for the two groups of students, at all undergraduate levels, were selected as a measure of how mathematics support impacts on student performance. The study showed that there was a substantial and significant difference between the marks achieved by students that engaged with support and those that did not. Students who engaged on average showed an $8 \%$ increase in their module mark compared with those who did not engage.
\end{abstract}

Keywords: Mathematics support, targeted lectures, module marks, quantitative analysis, impact.

\section{Introduction}

During the early 1990s it became apparent that the mathematical skills of undergraduate students entering higher education (HE) were not at the level expected by a range of disciplines. In science and engineering a significant number of new students to university were identified as being underprepared for the mathematical demands of their degree programmes. In response to this shortfall Coventry Polytechnic (now Coventry University) introduced an early form of mathematics support (MS) in 1991 which was mainly targeted at engineering students. A number of institutions in England followed Coventry's lead as detailed in a 1993 survey into the provision of mathematics support in further education (FE) and HE (Beveridge and Bhanot, 1994). The authors sent 800 questionnaires to FE and HE institutions across the UK and of the 142 that replied most offered some form of MS. From the mid-1990s an increasing number of institutions, including the University of Hull (1995) and Loughborough University (1996), launched mathematics support centres (MSCs). Lawson, Halpin and Croft (2001) reported that of the 95 UK universities who replied to their survey $48 \%$ provided some form of MS. The survey was updated in 2004 (Perkin and Croft, 2004) and 2012 (Perkin, Lawson and Croft, 2012) by which time 65\% and 85\% respectively of the institutions that replied offered mathematics support. In 2005 a collaborative bid to the Higher Education Funding Council for England (HEFCE) resulted in Coventry and Loughborough Universities being jointly awarded Centre for Excellence in Teaching and Learning (CETL) status. Following this award the sigma CETL project was launched to promote collaborative work in mathematics and statistics support in England and Wales. The funding for the project ended in 2010 and in the ensuing years it has evolved into the sigma Network. The Network continues the work of sigma CETL and is managed by volunteers, including representatives from Scotland and Ireland, who are involved with mathematics and statistics support in H.E.

The first MSC was opened in Ireland in the University of Limerick in 2001 and the Irish Mathematics Learning Support Network (IMLSN) was formed in 2009. A survey in 2015 by the IMLSN (Cronin et al., 2015) into the provision of MS in Ireland recorded that $83 \%$ of the institutions that replied offered 
mathematics and/or statistics support. In Scotland; one of the country's first mathematics drop-in centres was established in 1988 at Edinburgh Napier University (then, Napier Technical College). Over the years MS continued in various forms, on a largely informal basis, at universities across the country. In 2008 however the support community was brought together through the formation of the Scottish Mathematics Support Network (SMSN). A recent report (Ahmed et al., 2018) by the SMSN found that $78 \%$ of the Scottish institutions that responded provide mathematics and/or statistics support.

While it is somewhat unrealistic to claim that MS is the sole contributing factor to improvements in student grades and retention there is significant evidence that it plays a major role in enhancing the performance of those who engage with it. Across the MS community, at both a national and international level, it is therefore highly desirable to identify parameters that can provide a quantifiable measure of the impact of MS on student performance. In the past various studies have been carried out in an attempt to measure the effectiveness of MSCs. Pell and Croft (2008) observed that while data will generally show that MSCs are well-used and valued by students a much more powerful measure of their effectiveness would be provided by quantitative data comparing how students who use these centres perform in their mathematics examinations and whether failing students are those who do not use the centres.

Matthews et al. (2013) reviewed the literature to date and highlighted studies that provided a quantitative analysis of MSC usage as well as studies into the impact of MS on students' mathematical confidence and progression and retention rates. Gill and O'Donoghue (2013) analysed the grades of students attending mathematics service modules at the University of Limerick between 2000/01 and 2003/04. Based on their performance on a diagnostic test, taken early in the first term, students scoring below $50 \%$ were categorised as 'at risk' and offered support tutorials. To measure the effectiveness of this support end of term examination results were compared for students in the 'at risk' group, who attended the tutorials, with those in the group who did not participate. For each year of the study 'at risk' students who attended the support tutorials were observed to out-perform their counterparts who did not attend. Additionally, the opening of the Mathematics Learning Centre (MLC) in late 2001 resulted in a dramatic fall in failure rate providing supporting evidence for the benefits of MS.

In their work Gallimore and Stewart (2014) categorised 42 first year engineering students at the University of Lincoln into three groups according to their performance on a diagnostic test and the use they made of follow-up support tutorials. The three categories included:

- students needing minimal support;

- students needing support who made use of the tutorial sessions;

- students needing support who did not use the tutorial sessions.

The impact of the support was measured by analysing the correlation between diagnostic test marks and final exam marks. Analysis of the results indicated that while those in the second and third categories had similar diagnostic test marks there was a significant difference in their exam results. The students who used the tutorial sessions performed significantly better in the exam than those in the third category whose lack of understanding and basic skills became apparent.

Pell and Croft (2008) analysed data for 644 first year engineering students taking five mathematics modules at Loughborough University in order to measure the impact of the Mathematics Learning Support Centre (MLSC). The authors found evidence that MS had improved the pass rate by approximately $3 \%$ and some students obtained passes in their final exams and remained at the university when they may have otherwise failed and withdrawn. Surprisingly perhaps it was also observed that $35 \%$ of the highest achieving students had used the MLSC indicating that a considerable number of mathematically stronger students use the centre to improve their grades. 
These results were supported by a study carried out at the National University of Ireland, Maynooth by Mac an Bhaird et al. (2009). The authors found strong evidence to suggest that support played an important role in the retention of 'at risk' students as well as being used by strong students looking to improve their chances of achieving top grades.

\section{Background}

Glasgow Caledonian University is a post-1992 university, formed in 1993, through the merger of Glasgow Polytechnic with Queen's College. The student population in 2017/18 was approximately 15,000 with over 4,000 mature students and the largest number of part-time students in Scotland. International students from more than 100 countries study at GCU. The university is committed to the Scottish government's widening access initiatives which include advanced entry to university through articulation from the college sector and collaborating with schools across Scotland with traditionally low progression rates to H.E. These factors result in increasingly more entrants from diverse educational, social, and cultural backgrounds with widely varying experiences and knowledge of mathematics and statistics. Additionally, the introduction of new degree programmes, in areas such as computer games and audio technology, requires students to learn mathematical topics that they may not have been adequately prepared for in school or the college sector.

In 2008, in response to the increased numbers of students from non-traditional backgrounds entering university, GCU established a Learning Development Centre (LDC) in each of the university's three schools with funding coming from both the university and the Scottish Funding Council (SFC). The role of the LDC was to provide academic support to students with the initial focus in all three schools being on support for academic writing. In the School of Computing, Engineering and Built Environment (SCEBE) however it soon became apparent that the mathematical content in a significant number of the degree programmes was influencing student performance and hence retention, progression and completion rates. In 2012/13 SCEBE appointed a dedicated member of staff to the role of providing support for mathematics and statistics.

\subsection{Mathematics support in SCEBE}

In 2017/18 the student population in SCEBE was approximately 4,330 with an $80 \% / 20 \%$ male/female split and a $72 \% / 28 \%$ full-time/part-time split. The structure of SCEBE includes three departments: Engineering (ENG); Computer, Communications and Interactive Systems (CCIS); and Construction and Surveying (C\&S). Figure 1 shows the overall engagement with MS by students from these departments between 2013/14 and 2017/18. Clearly students from the Department of Engineering, accounting for $70 \%$ of all students, are the most prominent users of MS reflecting the significant mathematical content of their degree programmes when compared with programmes from the other two departments. 


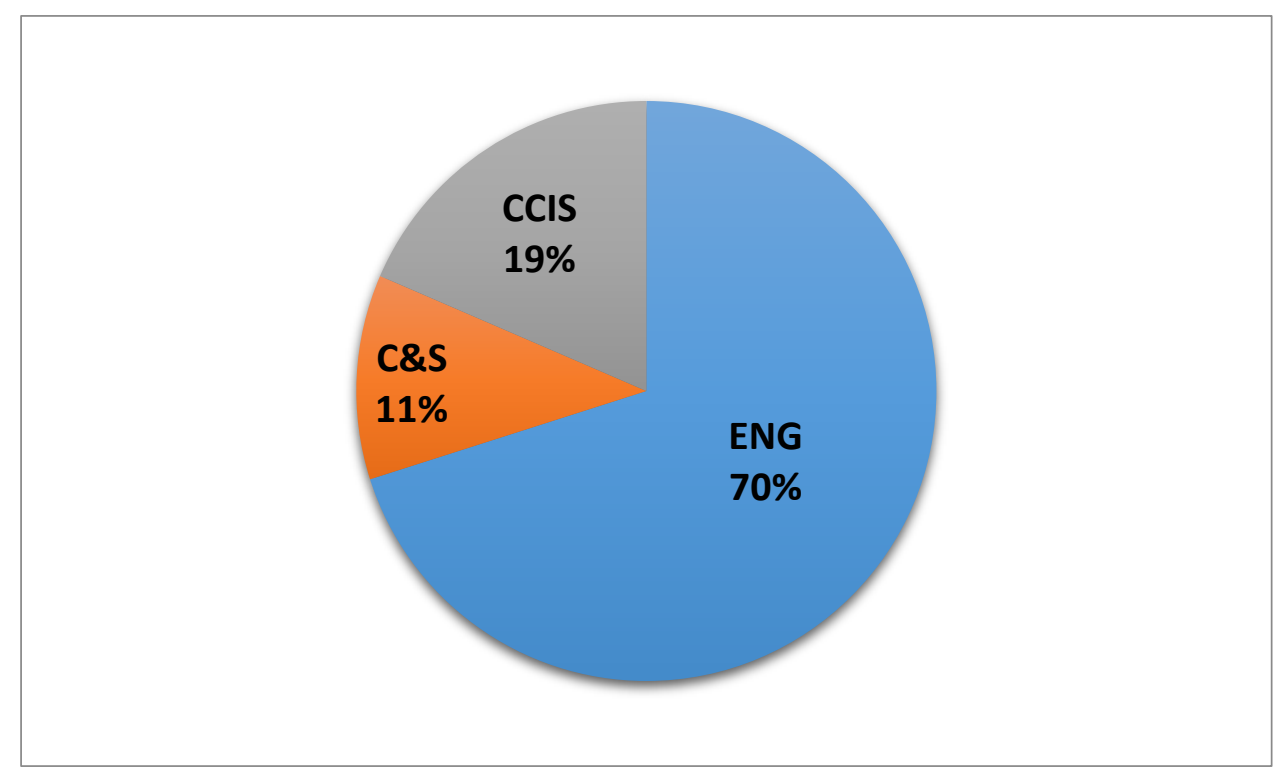

Figure 1: Engagement with MS by SCEBE department, 2013/14 - 2017/18

The main forms of support available in SCEBE include a mathematics summer school at pre-entry to university, diagnostic testing during induction and ongoing support from entry to completion. The ongoing support takes the form of:

- one-to-one and small group meetings - arranged on an appointment basis;

- drop-in sessions - students can visit the LDC between 9am and 5pm, without an appointment, to discuss their mathematics and statistics problems;

- targeted lectures - agreed with module and programme leaders to provide students with mathematics and statistics lectures on specific topics particular to their course;

- email - students can contact MS to discuss any difficulties they are experiencing. If these issues are not resolved a face-to-face meeting is arranged.

Figure 2 shows the distribution of contacts with MS, according to the type of support, between $2013 / 14$ and $2017 / 18$. Over the five year period there were over 2,000 contacts involving nearly 12,000 students. Targeted lectures are clearly the most popular mode of contact accounting for $40 \%$ of the total number. These weekly lectures are typically one hour in duration and appear on student timetables but attendance is on a voluntary basis. The material covered in class can include a revision of topics from previous years and/or providing a more in-depth treatment of new mathematical techniques. Students are issued with printed lecture notes that provide full explanations of relevant mathematical techniques, contain contextualised examples and extensive tutorial questions with full solutions. The notes and slide presentations can be accessed via the Blackboard Virtual Learning Environment (VLE) and contain appropriate links to mathematics support websites such as MathCentre (http://www.mathcentre.ac.uk) and Khan Academy (https://www.khanacademy.org). For some modules students can also access multiple choice tests on Blackboard authored using Maple TA software (https://www.maplesoft.com/products/maple). The Maple exercises provide students with immediate feedback in the form of answers and solutions. Furthermore, feedback is offered through questions asked during, or after, lectures and at one-toone and small group meetings.

The quality of the support offered by SCEBE is reflected in the member of staff being nominated by students in successive years for the GCU Students' Association Teaching Awards. Furthermore, the NSS in 2016/17 provided qualitative evidence of the high regard in which the service is held by 
students. A thematic analysis of student comments for the NSS identified several direct references to the value and effectiveness of MS in SCEBE.

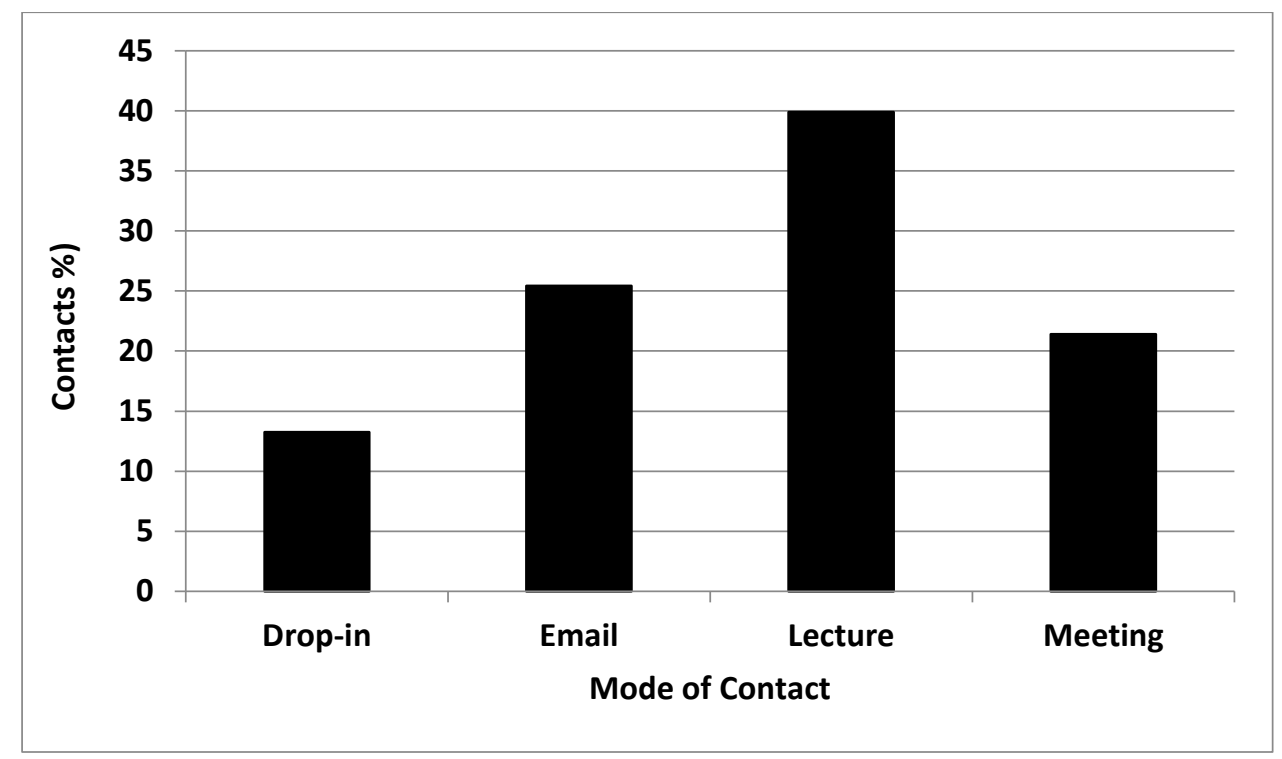

Figure 2: Modes of contact with MS for SCEBE students, 2013/14 - 2017/18

\section{Methodology}

The data used in this study were collected over the five year period from $2013 / 14$ to $2017 / 18$. Note that although MS started in 2012/13 a full data set was not available for that year. As discussed above the data relate to student engagement, and non-engagement, with MS through attendance at targeted lectures and the first diet module marks achieved by these students. Attendance at the targeted lectures was recorded using Student Attendance and Engagement Monitoring (SAEM) which is essentially a swipe card system. In order for a module to be considered for the study at least $10 \%$ of the cohort must engage with targeted lectures and only students attending $20 \%$, or more, of classes are included. For example, for a module with 100 registered students at least 10 students must have attended $20 \%$ or more of the targeted lectures. Over a trimester the $20 \%$ threshold translates to engagement with two or more classes which, as observed by Lawson et al. (2001), indicates that the students consider their previous experience to have been beneficial thereby making a return visit to the class worthwhile. Based on these criteria between $2013 / 14$ and $2017 / 18$ a total of 47 undergraduate modules qualified for analysis and of the 4,690 registered students on these modules 1,142 (24\%) engaged and 3,548 chose not to engage. The 47 modules range across all four levels of undergraduate study and some contribute to the data for each of the five years while others may only appear once due to factors such as being discontinued following a portfolio refresh. The study involved a total of 18 different modules as detailed in Appendix A. Figure 3 shows the distribution of the 1,142 engaging students and their parent department. The majority of engaging students (51\%) are from the Engineering department as the modules these students study contain a significant mathematical element across all levels of study. 


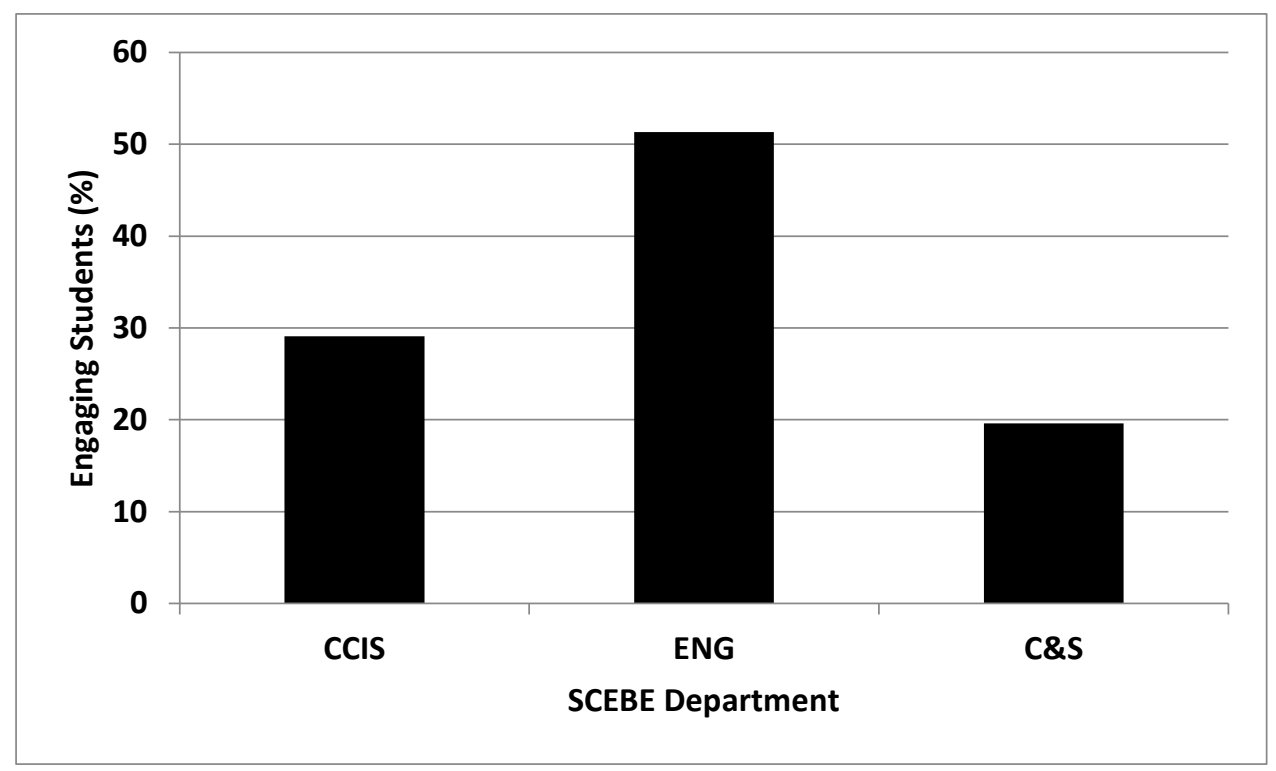

Figure 3: Distribution of students engaging with MS by department, 2013/14 - 2017/18

A point to note is that a small number of modules, especially in first and second year, are taught to students from more than one department. Engineering mathematics modules at Levels 1 and 2 are Department of Engineering modules but students from C\&S also attend these modules. Hence, although C\&S does not itself offer mathematics modules the department is included in Figure 3 as $20 \%$ of engaging students were registered with C\&S.

Figure 4 shows how the 1,142 engaging students are distributed across the four undergraduate levels of study. Over $60 \%$ of these students are registered on modules at Levels 3 and 4 . All Level 4 students come from Engineering programmes, while at Level 3 a total of $75 \%$ are from Engineering with the remaining $25 \%$ from CCIS. No C\&S students participate in modules taught at Levels 3 and 4 for which targeted lectures are offered. The high number of students in their final two years of study engaging with MS can be attributed to several factors including; Levels 3 and 4 modules involving more advanced mathematics and module marks contributing to the final degree classification. Furthermore, a significant number of students in third year have articulated to GCU from the college sector and tend to engage with MS in greater numbers than continuing students. It is worthwhile noting that in $2017 / 18,53 \%$ of third year students in the Department of Engineering were articulating students. 


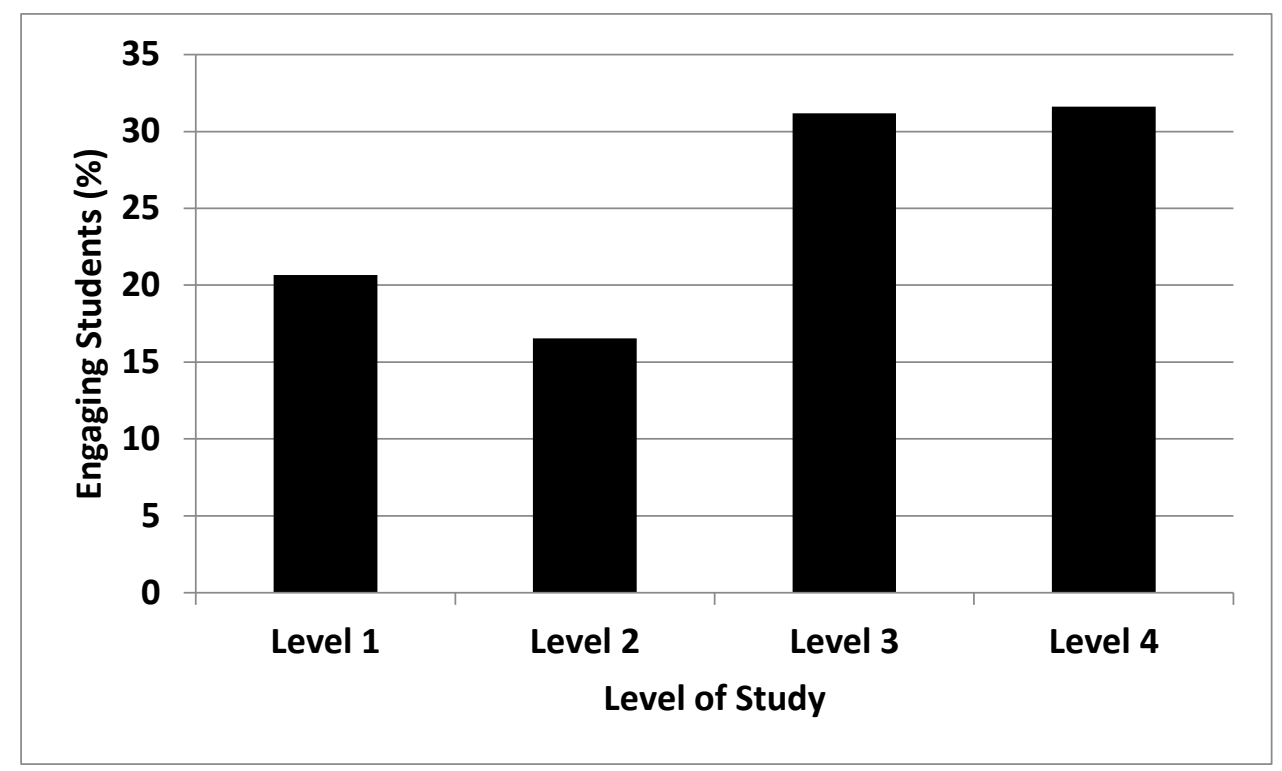

Figure 4: Distribution of students engaging with MS by level (year) of study, 2013/14 - 2017/18

\section{Results}

The majority of the modules featured in the study included an element of coursework and a final exam with the marks being combined to produce a module mark. In each year the average mark for each module was calculated for both engaging and non-engaging students. These average module marks were then themselves averaged to produce an average mark for that specific year for both groups of students. The results are plotted in Figure 5. It can be seen that for these modules students who engage with MS, by attending targeted lectures, clearly out-perform their counterparts who choose not to engage. When the marks for the 47 modules were averaged, to give a 5 year average, engaging students recorded a mark of $61 \%$ and non-engaging students $53 \%$. Over the period engagement with MS therefore resulted in an $8 \%$ improvement in the average module mark. A point worthwhile noting is that of the 47 modules under consideration students who engaged with MS recorded a higher average mark for $39(83 \%)$ of these modules.

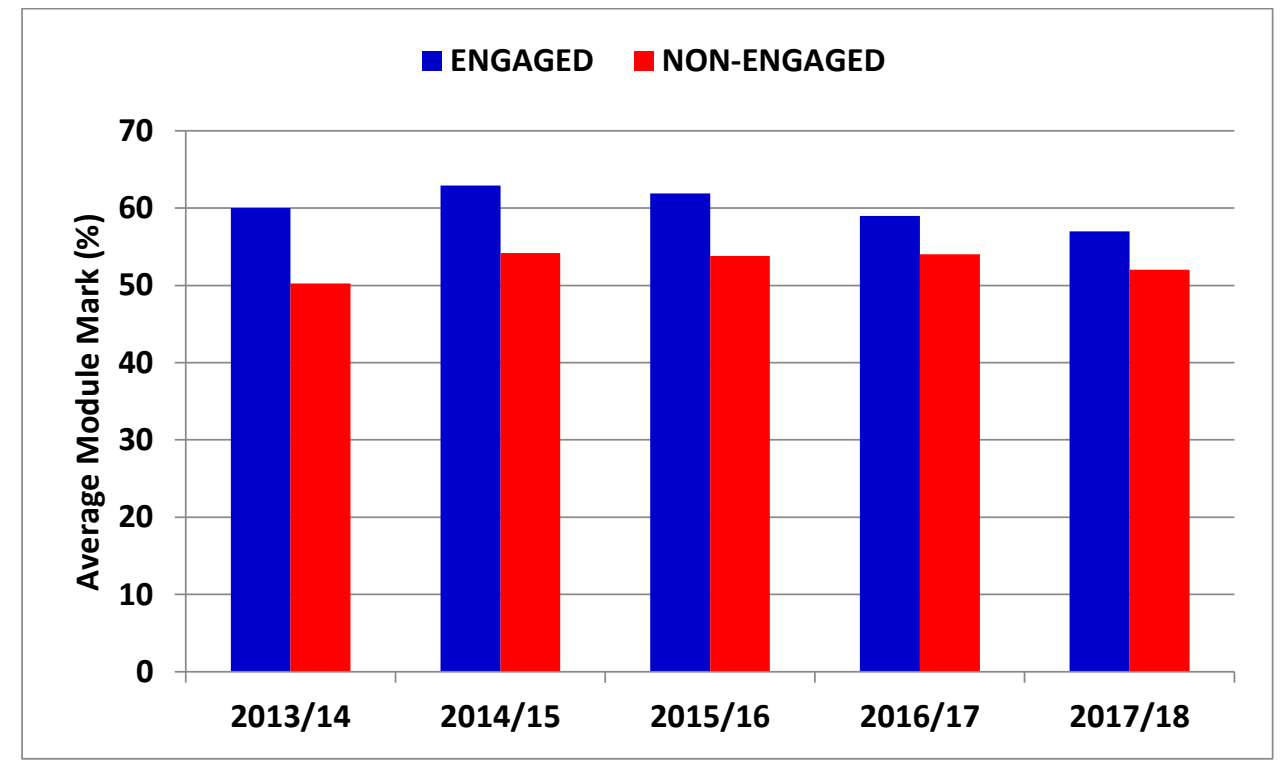

Figure 5: Average first year module mark for students engaging and not engaging with MS, $2013 / 14-2017 / 18$ 
Figure 6 shows the average module mark achieved by engaging and non-engaging students over the period according to their level of study. It is clear that attendance at targeted lectures has resulted in an increase in module mark at all four levels. Over the first three levels the gap between the two groups closes from one level to the next which can perhaps be attributed to an improvement in students' mathematical skills and confidence growth as they progress on their degree programmes. At Level 4 however the gap increases to $9 \%$ emphasising the importance of engagement with MS in the Honours year. One influencing factor that has been identified through discussions with students is that of conflicting priorities where they spend a disproportionate amount of time on their Honours project at the expense of their other modules and attendance at targeted lectures.

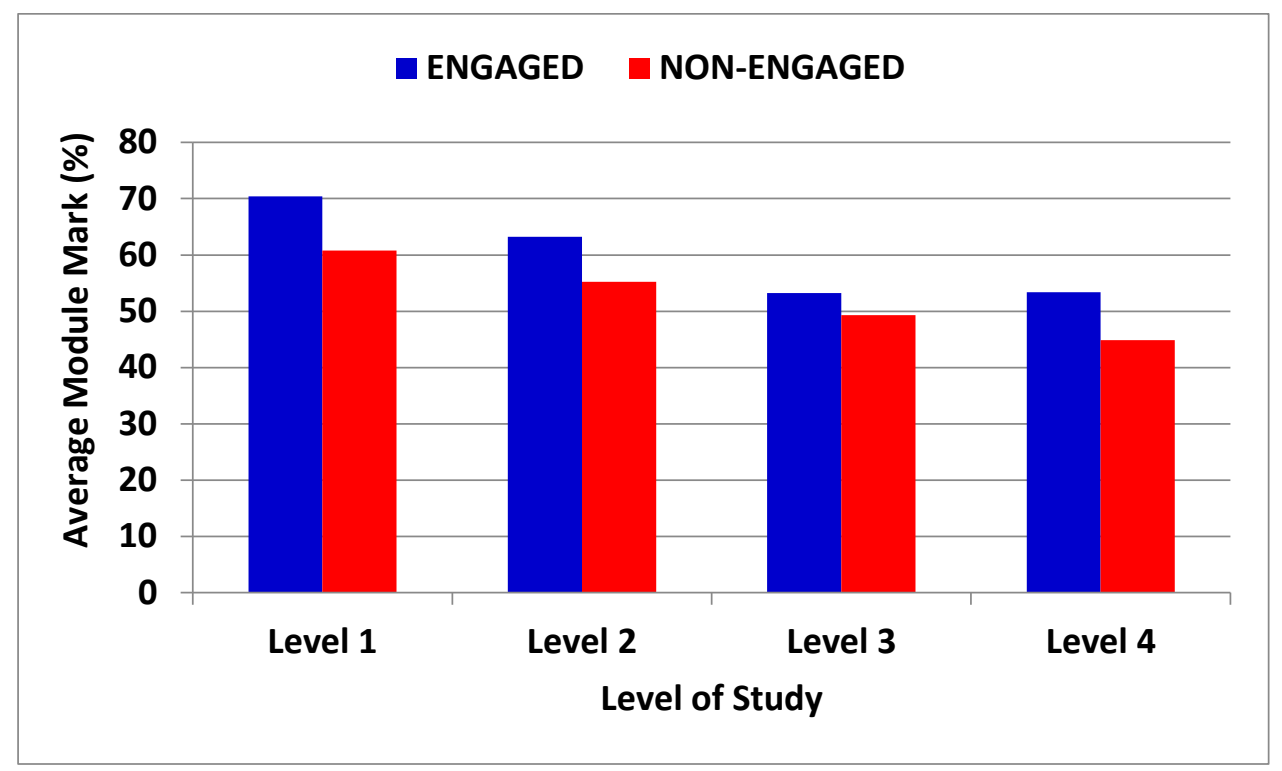

Figure 6: Average module mark by level (year) of study for students engaging and not engaging with MS, 2013/14 - 2017/18

\section{Conclusions}

First diet module marks for 4,690 undergraduate students, at all levels of study, were recorded over a five year period for those who engaged with MS, through attendance at targeted lectures, and those who did not engage. The data showed that attendance at targeted lectures resulted in an $8 \%$ improvement in the average module mark for engaging students when compared with the mark for non-engaging students. It should be noted that many of the students who attended the targeted lectures also used other forms of MS such as small group meetings and the drop-in facility. Clearly MS, and attendance at targeted lectures, cannot take all the credit for the results described here as other factors such as students' attendance at module lectures and tutorials influence their performance. Additionally, students engage with external support mechanisms such as tutors and online materials to enhance their understanding. Peer support also plays an important role with students forming study groups to work on aspects of modules, particularly mathematical topics, that prove challenging. Nevertheless, the results presented here are encouraging and provide a quantitative measure of the impact and effectiveness of MS on student performance and retention; a fact further supported by qualitative evidence from the NSS in 2016/17.

Looking to the future one aim would be to increase the number of students engaging with MS and ultimately improve performance and completion rates. Since MS was introduced in SCEBE in $2012 / 13$ the number of student contacts has increased annually growing by $115 \%$ over the period and exceeding 3,000 in $2017 / 18$. Incentives such as targeted lectures, which are included on student 
timetables, and offering contextualised mathematical material at module sites on the Blackboard VLE have contributed significantly to MS engagement. Numbers could perhaps be increased further by, for example, making attendance at targeted lectures compulsory for students who score below a pre-set threshold on the mathematics diagnostic test offered during induction. However, such a radical amendment to timetables is an institutional matter and in order to achieve these goals adequate resources such as staff and space, as identified by Cronin et al. (2015) and Ahmed et al. (2018) are essential.

\section{Appendix}

Table 1: School of Computing, Engineering \& Built Environment modules qualifying for the study; level of module and number of years targeted lectures delivered.

\begin{tabular}{|l|c|c|}
\hline Module & Level & $\begin{array}{c}\text { No. of years targeted } \\
\text { lectures delivered }\end{array}$ \\
\hline Mathematics for Computer Games 1 & 1 & 4 \\
\hline Discrete Mathematics & 1 & 3 \\
\hline Engineering Mathematics & 1 & 4 \\
\hline Mathematics for Computing & 1 & 2 \\
\hline Mathematics 1 & 1 & 1 \\
\hline Mathematics \& Statistics of Experimentation & 2 & 3 \\
\hline 3D Mathematics for Simulation and Visualisation1 & 2 & 3 \\
\hline Data Communications \& Transmission Systems & 2 & 1 \\
\hline Mathematics 2 & 2 & 2 \\
\hline Mathematics 2A & 2 & 5 \\
\hline Mathematics 2B & 3 & 3 \\
\hline 3D Mathematics for Simulation and Visualisation & 3 & 5 \\
\hline Control Engineering 3 & 3 & 4 \\
\hline Plant \& Electrical Distribution Systems & 3 & 2 \\
\hline Quantitative Modelling and Cryptography & 4 & 2 \\
\hline Control Engineering 4 & 1 & 2 \\
\hline Digital Signal Processing & 2 & 2 \\
\hline Power Systems Technology & 2 & 2 \\
\hline
\end{tabular}

Note that in 2016/17 the Level 3 module, 3D Mathematics for Simulation and Visualisation was revised and re-assigned as a Level 2 module.

\section{References}

Ahmed S., Davidson P., Durkacz K., Macdonald C.A., Richard M., and Walker A., 2018. The Provision of Mathematics and Statistics Support in Scottish Higher Education Institutions (2017) - A Comparative Study by the Scottish Mathematics Support Network. MSOR Connections, 16(3), pp.519. 
Beveridge, I., and Bhanot, R., 1994. Maths support survey. Mathematics Support Association Newsletter 1, p.13. Available at: http://www.sigma-network.ac.uk/wp-content/uploads/2018/11/MSANewsletter-1-Spring-1994.pdf [Accessed 11 March 2019].

Cronin, A., Cole, J., Clancy, M., Breen, C., and O Se, D., 2015. An audit of mathematics learning support provision on the island of Ireland in 2015. National Centre for Excellence in mathematics and Science Teaching and Learning (NCE-MSTL), University of Limerick, Republic of Ireland. Available at: https://pure.qub.ac.uk/portal/files/135272903/MLS Ireland survey 2015.pdf [Accessed 11 March October 2019].

Gallimore, M., and Stewart, J., 2014. Increasing the impact of mathematics support on aiding student transition in higher education. Teaching Mathematics and Its Applications, 33(2), pp.98-109.

Gill, O., O' Donoghue, J., and Johnson, P., 2008. An audit of mathematics support provision in Irish third level institutions. Regional Centre for Excellence in Mathematics Teaching and Learning, University of Limerick, Republic of Ireland. Available at: https://www3.ul.ie/cemt//pdf\%20files/FullAudit.pdf [Accessed 11 March 2019].

Lawson, D., Croft, A.C., and Halpin, M., 2003. Good Practice in the Provision of Mathematics Support Centres, 2nd edition. Birmingham: LTSN Maths, Stats \& OR Network. Available at: https://www.heacademy.ac.uk/system/files/GoodPracticeProvision.pdf [Accessed 11 March 2019].

Lawson, D., Halpin, M., and Croft, A.C., 2001. After the diagnostic test - what next? MSOR Connections, 1(3), pp.19-23.

Mac an Bhaird, C., Morgan, T., and O'Shea, A., 2009. The impact of the mathematics support centre on the grades of first year students at the National University of Ireland Maynooth. Teaching Mathematics and Its Applications, 28, pp.117-122.

Matthews, J., Croft, A.C., Lawson, D.A., and Waller, D., 2013. Evaluation of mathematics support centres: a literature review, Teaching Mathematics and Its Applications, 32 (4), pp.173-190.

Pell, G., and Croft, A.C., 2008. Mathematics Support - support for all? Teaching Mathematics and Its Applications, 27 (4), pp.167-173.

Perkin, G., and Croft, A.C., 2004. Maths Support Centres - the extent of current provision, MSOR Connections, 4 (2), pp.14-18.

Perkin, G., Lawson, D., and Croft, A.C., 2012. Mathematics learning support in UK higher education: the extent of provision in 2012, The National HE STEM programme. Available at: http://www.mathcentre.ac.uk/resources/uploaded/52789-mls-in-uk.pdf [Accessed 11 March 2019]. 